\title{
ESTUDO DA GERMINAÇÃO DE SEMENTES DE ESPÉCIES ARBÓREAS PIONEIRAS: TIBOUCHINA PULCHRA COGN. E TIBOUCHINA GRANULOSA COGN. (MELASTOMATACEAE)
}

\author{
José Eduardo Zaia' \\ Massanori Takaki ${ }^{2}$
}

Recebido em 18/06/1998. Aceito em 17/11/1998

\begin{abstract}
RESUMO - ( Estudo da germinação de sementes de espécies arbóreas pioneiras: Tibouchina pulchra Cogn. e Tibouchina granulosa Cogn. (Melastomataceae)). A influência da luz no processo de germinação de sementes de Tibouchina pulchra e T. granulosa foi estudada. Sementes de Tibouchina pulchra e T. granulosa submetidas a diferentes qualidades e quantidades de luz demonstram forte dependência para o processo de germinação. Em condições de escuro e irradiação com vermelho-extremo, as sementes não germinaram, demonstrando o envolvimento do fitocromo no processo, como evidenciado através de curvas de fluência-resposta e de curvas de escape da ação do fitocromo. Após 12 meses de estocagem sob baixa temperatura as sementes apresentaram a mesma percentagem de sementes viáveis. A partir destes resultados conclui-se que $T$. pulchra and $T$. granulosa são espécies pioneiras.
\end{abstract}

Palavras-chave - espécies pioneiras, germinação de sementes, fitocromo, Tibouchina

\begin{abstract}
Seed germination of pioneer species of Tibouchina pulchra Cogn. and Tibouchina granulosa Cogn. (Melastomataceae)). Seeds of Tibouchina pulchra and T. granulosa submitted to different light treatments showed light dependence of the germination process. In conditions of complete darkness and when submitted to far-red light. seeds did not germinate, demonstrating the involvement of phytochrome in the process. This conclusion was corroborated by curves of fluence response for seed germination and escape curves of phytochrome action. Seeds of both species presented the same percentage of viable seeds after twelve months storage under low temperature. Our results indicates that $T$. pulchra and $T$. gramulosa are pioneer species.
\end{abstract}

Key words - pioneer species, seed germination, phytochrome. Tibouchina

\section{Introdução}

A quantidade e a qualidade espectral da luz, disponíveis para a germinação de sementes, são distintas nas diferentes situações da floresta tropical natural (Lopes-Quiles \& Vazquez-Yanes 1976; Vazquez-Yanes et al. 1990). A luz pode tanto promover quanto inibir a germinação, até mesmo em sementes da mesma espécie. Algumas sementes

Departamento de Ciências Biológicas, Universidade de Franca, Av. Dr. Armando de Salles Oliveira 201, CEP 14.404-600, Franca, SP. Brasil

: Departamento de Botânica. UNESP, C. Postal 199. CEP 13506-900. Rio Claro, SP, Brasil 
fotoblásticas positivas são inibidas por irradiações prolongadas com luz branca policromática (Bartley \& Frankland 1982).

A regeneração de florestas tropicais a partir de sementes de espécies arbóreas pioneiras é dependente da ocorrência de clareiras na vegetação. As clareiras proporcionam a entrada de novos indivíduos, novos genótipos e novas espécies na vegetação e, por esta razão, este assunto tem merecido a atenção de vários autores (Denslow 1980; Ewel 1980; Augspurger 1984; Brokaw 1987; Canham et al. 1990; Kapos et al. 1990). Experimentos de germinação em condições naturais têm mostrado que a luz difusa da floresta, filtrada pelo dossel, é inibidora para sementes fotossensíveis, pelo fato desta luz ser rica em vermelho-extremo (Smith 1973). Um fator de fundamental importância no processo de germinação é a percepção pelo fitocromo, contido nas sementes, das proporções relativas de luz vermelha (V) e vermelho-extremo (VE). Dessa forma, a luz filtrada pelo dossel, apresentando baixa relação V/VE mantém baixo fotoequilíbrio do fitocromo, inibindo a germinação de sementes de plantas heliófilas quando se disseminam sob o dossel da floresta (Vazquez-Yanes \& Orozco-Segovia 1984; Casal \& Smith 1989). Smith (1986) sugere que o requerimento de luz para a germinação é particularmente um fenômeno de sementes pequenas, as quais envolvem não somente várias espécies herbáceas, como também sementes de árvores de espécies pioneiras, estas usualmente as primeiras a germinarem em clareiras grandes.

Em estudos sucessionais recentes na Mata Atlântica (Mendonça et al. 1992; Rolim et al. 1992), foi observada a presença marcante de espécies do gênero Tibouchina como principais colonizadoras de áreas degradadas. Além de sua importância ecológica, várias espécies deste gênero são utilizadas em arborização de ruas e praças como, por exemplo, T. fothergillae, $T$. moricantiana, $T$. granulosa e $T$. sellowiana, entre outras. Tibouchina pulchra, comumente conhecida como manacá-da-serra, ocorre desde o Estado do Rio Grande do Sul até São Paulo e T. granulosa, conhecida como quaresmeira, pode ser encontrada nos Estados de São Paulo, Rio de Janeiro, Minas Gerais, Paraná e Bahia.

No presente trabalho é descrito o efeito da luz e o tempo de armazenamento na germinação de sementes de Tibouchina pulchra e $T$. granulosa.

\section{Material e métodos}

Foram utilizadas sementes de Tibouchina pulchra Cogn. e de Tibouchina granulosa Cogn. coletadas a partir de árvores localizadas no campus da UNESP, município de Rio Claro, SP. Os testes de germinação foram realizados utilizando-se quatro placas de Petri de $5 \mathrm{~cm}$ diâm., contendo duas camadas de papel de filtro embebidas em água destilada. O número de sementes utilizado em cada tratamento variou entre 100 e 200 sementes por placa de Petri. As contagens foram realizadas com o auxílio de lupa ao final de cada ensaio, e em seguida, determinada a percentagem de germinação, conforme descrito por Cone (1985) para sementes de Arabidopsis thaliana. O número de sementes germinadas foi monitorado sob luz verde de segurança (Kendrick \& Frankland 1969).

As sementes das duas espécies foram mantidas em frascos âmbar fechados e armazenados em refrigerador (cerca de $10^{\circ} \mathrm{C}$ ). Uma parte das sementes coletadas foi 
mantida no escuro a $25^{\circ} \mathrm{C}$ em 16 placas de Petri contendo solução de agar $1 \%$ em água destilada, conforme Vazquez-Yanes \& Orozco-Segovia (1990). A cada período de três meses foram retiradas quatro placas de cada espécie para teste de viabilidade, até que se completassem 12 meses. Os testes de germinação consistiram em expor as sementes à luz branca fluorescente de $26,77 \mu \mathrm{W} . \mathrm{cm}^{-2}$ por período de 30 dias, após os quais era obtida a percentagem de germinação.

No experimento de curva de fluência-resposta as diferentes irradiâncias, medidas com espectroradiômetro (LI-COR 1800) foram obtidas variando-se o número de lâmpadas e a distância entre as sementes e a fonte luminosa em câmara climática (Takaki et al. 1985). Para as irradiações saturantes de $\mathrm{V}\left(10.5 \mu \mathrm{W} . \mathrm{cm}^{-2}\right)$ foram utilizadas duas camadas de papel celofane vermelho sob luz fluorescente luz-do-dia (Philips 15W); para as irradiações de VE $\left(46,5 \mu \mathrm{W} . \mathrm{cm}^{-2}\right)$ foram utilizadas duas camadas cada de papel celofane vermelho e azul sob luz incandescente (Osram 25W). A influência do fotoperíodo $(2,4,6$ e 8 horas) sobre a indução da germinação foi determinado em estufas incubadoras para BOD com luz branca de $26,77 \mu \mathrm{W} . \mathrm{cm}^{-2}$.

As curvas de escape da ação do fitocromo foram obtidas mantendo as sementes em estufa incubadora para BOD sob fotoperíodo de oito horas de luz $\mathrm{V}$ seguido de irradiação VE por 15 minutos, com o intervalo entre a irradiação $\mathrm{V} \mathrm{e} \mathrm{VE} \mathrm{variando} \mathrm{de}$ zero até 14 horas de escuro. Como controle foram utilizadas as sementes mantidas sob fotoperíodo de luz V, sem irradiação com a luz VE. A temperatura para todos os experimentos foi de $25^{\circ} \mathrm{C}$.

A significância da percentagem de germinação entre os tratamentos foi obtida com base no teste de Tukey, com a transformação dos dados em arcoseno da raiz quadrada de P/100 e ao nível de significância de 5\% (Snedecor \& Cochran 1967).

As percentagens finais de germinação foram utilizadas para a obtenção de funções de Gompertz, para ajustes das curvas de fluência-resposta e curvas de escape (Trexler et al. 1988), de acordo com a equação: $\mathrm{W}=$ a $\operatorname{EXP}(-b \operatorname{EXP}(-k t)$. Para a obtenção dos parâmetros da equação de Gompertz foi utilizado o programa descrito por Calbo et al. (1989).

\section{Resultados}

O tempo mínimo necessário para a germinação das sementes foi de sete dias para as duas espécies estudadas (Fig. 1). A percentagem máxima de germinação ocorreu a partir do $15^{\circ}$ dia para T. pulchra e do oitavo dia para T. granulosa. Apesar das percentagens de germinação serem relativamente baixas (em torno de $30 \%$ para $T$. pulchra e $15 \%$ para $T$. granulosa), elas refletem a percentagem máxima de cada espécie, uma vez que grande número de sementes não possui embrião, conforme verificado visualmente com o uso de microscópio óptico nas sementes que não germinaram. Sementes estocadas por 12 meses a baixas temperaturas não perderam viabilidade (Tab. 1).

Os tratamentos de luz demonstraram que as sementes de ambas as espécies apresentam forte dependência da luz (Branca ou Vermelha) para iniciarem o processo de germinação, apresentando resposta nula quando colocadas no escuro ou sob irradiação VE (Tab. 1). Com relação ao fotoperíodo, as respostas apresentadas diferiram consideravelmente entre os tratamentos, demonstrando que T. pulchra necessita de pelo 


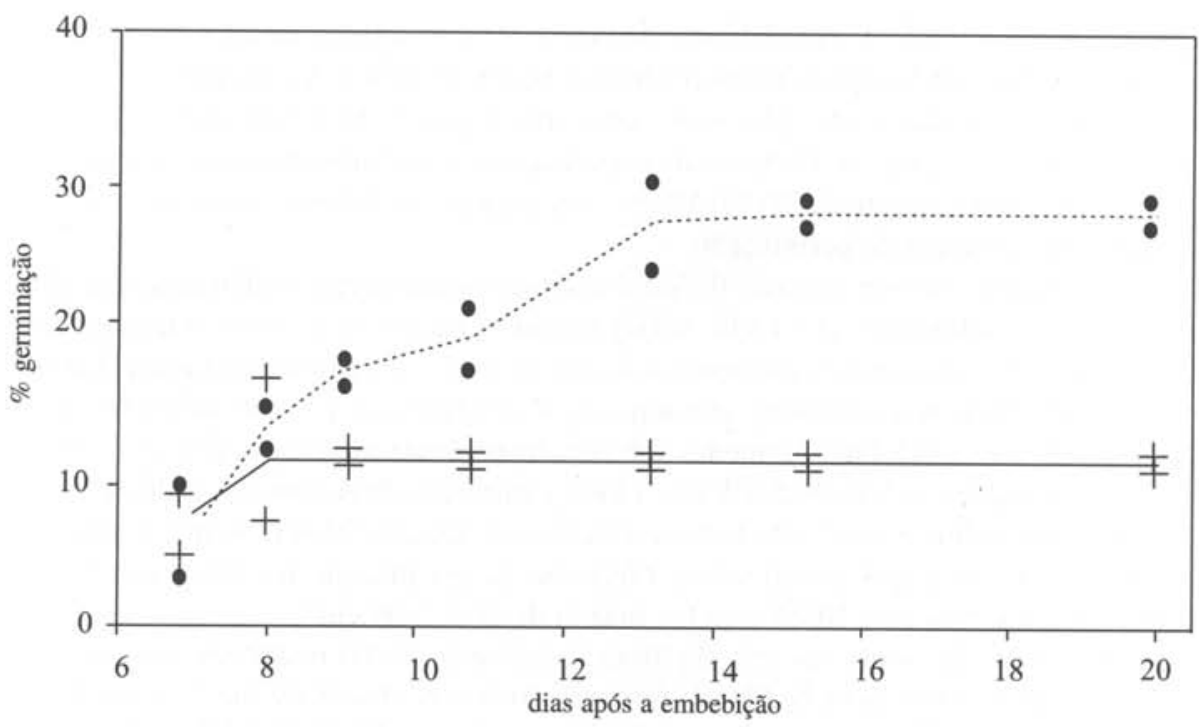

Figura 1. Curvas de germinação para sementes de Tibouchina pulchra (linha tracejada) e T. granulosa (linha sólida). Sementes embebidas no escuro por 24 horas. Experimento conduzido sob luz branca $\left(26,77 \mu \mathrm{W} / \mathrm{cm}^{2}\right)$.

menos seis horas diárias de luz para a indução da germinação, enquanto T. granulosa necessita pelo menos duas horas diárias de luz para a indução da germinação (Tab. 1).

As curvas de fluência-resposta indicam que a intensidade luminosa pouco influenciou a percentagem final de germinação (Tab. 1). As curvas de regressão indicam que as sementes de $T$. granulosa apresentam saturação de resposta com irradiâncias próximas de $10 \mu \mathrm{W} . \mathrm{cm}^{-2}$, enquanto sementes de $T$. pulchra apresentam saturação com cerca de $15 \mu \mathrm{W} . \mathrm{cm}^{-2}$ (Fig. 2).

As curvas de regressão para o tempo de escape da ação do fitocromo (Fig. 3) demonstram que as sementes de $T$. granulosa apresentam tempo de escape menor que sementes de $T$. pulchra.

\section{Discussão}

O tempo mínimo de sete dias sob luz branca para se iniciar a germinação nas duas espécies, relativamente rápido se comparado a algumas espécies arbóreas nativas, pode ser considerado como adaptação à forma de vida pioneira. Devido à grande competição existente entre plântulas em habitats de clareira, indivíduos que emergem mais cedo podem apresentar certa vantagem competitiva sobre aqueles que emergem tardiamente, como sugere Garwood (1983).

As sementes de ambas as espécies se mostraram totalmente sensíveis à luz (Branca ou Vermelha), apresentando resposta nula de germinação quando mantidas no escuro ou sob irradiação VE. Sementes que apresentam tal tipo de resposta, comumente denominadas fotoblásticas positivas, são características de espécies pioneiras (Smith 1973; Frankland \& Taylorson 1983; Cone \& Kendrick 1986). O fotoblastismo é, 
Tabela 1. Percentagens médias de germinação apresentadas por tratamentos de luz e tempo de estocagem para sementes de Tibouchina pulchra e $T$. granulosa. Médias seguidas por letras distintas para uma mesma espécie dentro de um mesmo tratamento, diferem entre si ao nivel de significância de $5 \%$ de acordo com o teste de Tukey.

\begin{tabular}{|c|c|c|}
\hline Tratamento & T. pulchira & T. granulosa \\
\hline \multicolumn{3}{|l|}{ Tipo de luz } \\
\hline branca & 18.98 a & 14,89 a \\
\hline vermelha & $27.60 \mathrm{a}$ & $19,29 \mathrm{~b}$ \\
\hline vermelho extremo & 0 & 0 \\
\hline escuro & 0 & 0 \\
\hline \multicolumn{3}{|l|}{ Fotoperiodo } \\
\hline luz contínua & 27.84 a & 23,92 a \\
\hline 8 horas & 26,89 a & $20.42 \mathrm{a} \mathrm{b}$ \\
\hline 6 horas & $15.53 \mathrm{~b}$ & $11,43 \mathrm{c}$ \\
\hline 4 horas & $2.87 \mathrm{c}$ & $13,52 \mathrm{c}$ \\
\hline 2 horas & $4.39 \mathrm{c}$ & $16,61 \mathrm{bc}$ \\
\hline \multicolumn{3}{|c|}{ Fluência Resposta $\left(\mathrm{mW} / \mathrm{cm}^{2}\right)$} \\
\hline 26.77 & $28.43 \mathrm{ab}$ & $19.47 \mathrm{ab}$ \\
\hline 14.77 & 30,92 a & 24.92 a \\
\hline 8.77 & $27.59 \mathrm{ab}$ & $17,95 \mathrm{ab}$ \\
\hline 5.77 & $20.70 \mathrm{~b}$ & $15,00 \mathrm{~b}$ \\
\hline 4.27 & $20.63 \mathrm{~b}$ & $17.51 \mathrm{ab}$ \\
\hline 3.52 & $22.43 \mathrm{ab}$ & $19.28 \mathrm{a} \mathrm{b}$ \\
\hline \multicolumn{3}{|c|}{ Escape (horas de escuro) } \\
\hline controle * & 23,89 a & 20,42 a \\
\hline 14 & $11,62 \mathrm{~b}$ & 21,13 a \\
\hline 12 & $8.23 \mathrm{bc}$ & $16,86 \mathrm{a} \mathrm{b}$ \\
\hline 10 & $7.16 \mathrm{c}$ & $12,60 \mathrm{~b}$ \\
\hline 8 & $0.03 \mathrm{~d}$ & $0.87 \mathrm{c}$ \\
\hline \multicolumn{3}{|l|}{ Estocagem } \\
\hline recém coletada & 27,84 a & 23,92 a \\
\hline $12 \operatorname{meses}\left(10^{\circ} \mathrm{C}\right)$ & $28.43 \mathrm{a}$ & $19.47 \mathrm{a}$ \\
\hline
\end{tabular}

Fotoperiodo de 8 horas de luz vermelha sem irradiação com vermelho-extremo.

provavelmente, o mais importante mecanismo pelo qual as sementes podem detectar clareiras na vegetação, como é o caso de Cecropia obtusifolia, Piper auritum, Trema micrantha, Verbesina greenmanii, entre outras (Vazquez-Yanes \& Orozco-Segovia 1984; Brokaw 1987).

Os testes de armazenamento revelaram que as sementes de ambas as espécies mantêm a viabilidade por longo perípdo de tempo, demonstrando comportamento típico apresentado pela maioria das espécies arbóreas pioneiras que formam o banco de sementes em florestas tropicais.

A resposta apresentada pelas sementes quanto à intensidade luminosa, representada através das curvas de fluência resposta, foi semelhante para as duas espécies. A 


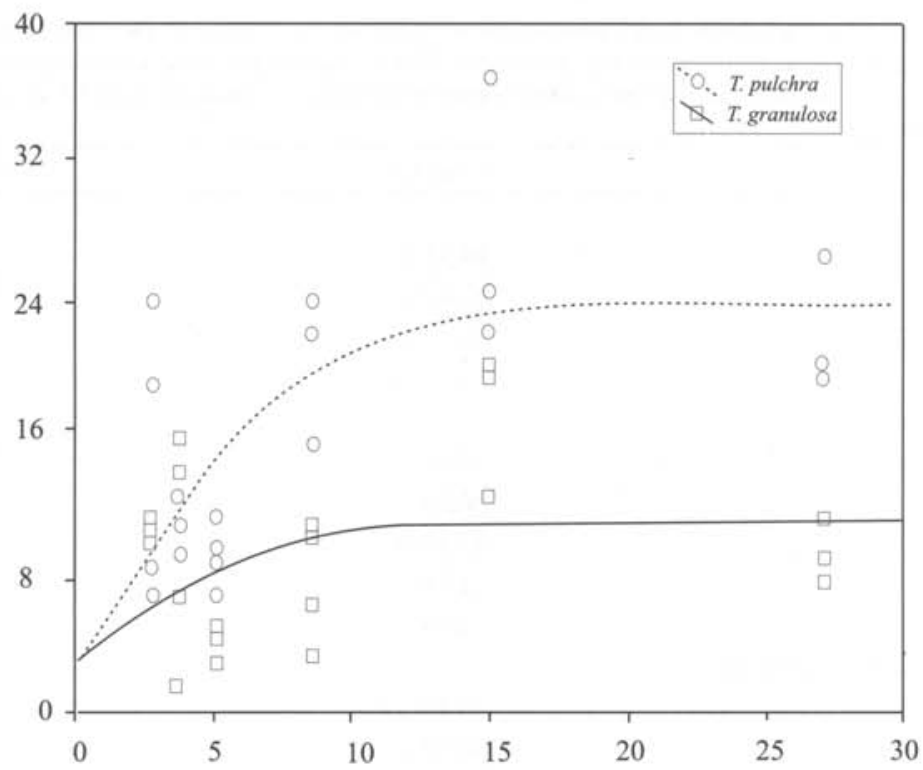

Figura 2. Curvas de fluência resposta para sementes de T. pulchra e T. granulosa. Sementes embebidas no escuro por 24 horas. Parâmetros da função Gompertz: $\mathrm{W}=\mathrm{a} \operatorname{EXP}(-\mathrm{b} \operatorname{EXP}(-\mathrm{kt}))$ : $T$. pulchra a $=24,625$; $\mathrm{b}=2,341$ e $\mathrm{k}=0,316$. $T$. granulosa: $\mathrm{a}=13,390 ; \mathrm{b}=1,684$ e $\mathrm{k}=0,338$.

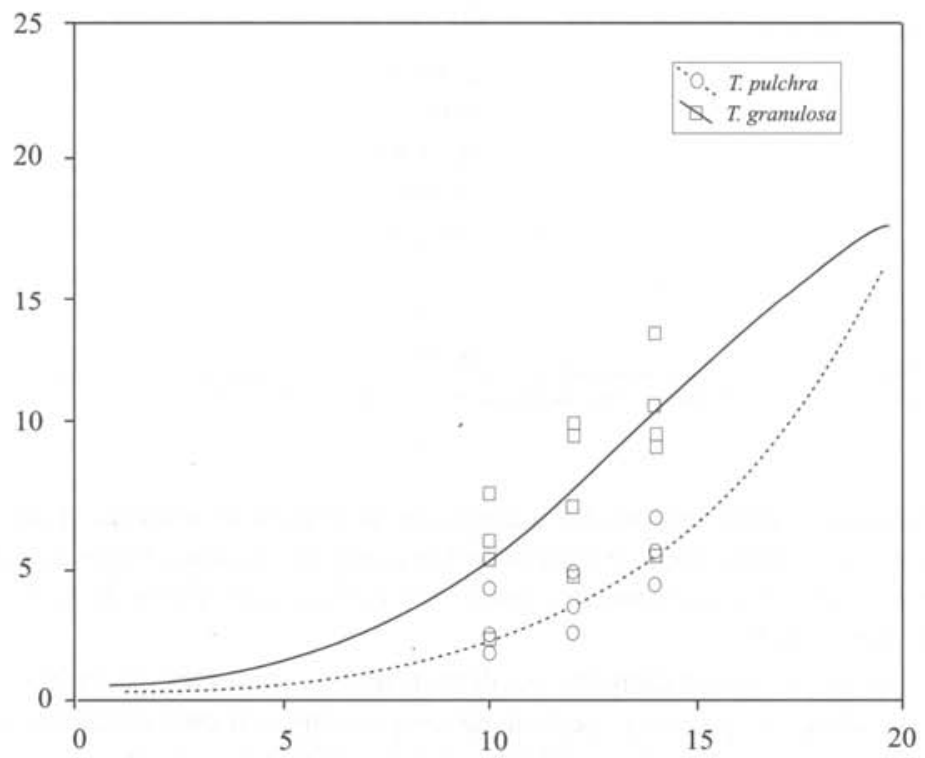

Figura 3. Curvas de escape da ação do fitocromo para sementes de $T$. pulchra e T. granulosa. Sementes embebidas no escuro por 24 horas. Experimento conduzido sob fotoperíodo de 8 horas de luz vermelha, diferentes períodos de escuro, seguido de 15 min de luz vermelho-extremo. Parâmetros da função Gompertz: W = a EXP(-b EXP(kt)): $T$. pulchra: $a=187,006 ; \mathrm{b}=15,063$ e k=0,024. $T$. granulos $a$ : $a=28,92 ; b=13,053$ e k=0,199. 
percentagem de germinação das sementes de ambas as espécies, de acordo com o teste de Tukey, foi praticamente a mesma dentro da amplitude de 3,52 a $26,77 \mu \mathrm{W} / \mathrm{cm}^{2}$. Tendo em vista que as sementes de T. pulchra e T. gramulosa não germinam no escuro, a saturação de indução da germinação ocorre em baixas irradiâncias, conforme regressões obtidas a partir de dados experimentais (Fig. 2). Tais resultados corroboram a afirmativa de que para as sementes fotoblásticas de árvores pioneiras o fator inibidor da germinação não é a irradiância, mas sim a relação V/VE da luz difusa que chega até as sementes (Vazquez-Yanes \& Orozco-Segovia 1984). Goldman et al. (1989) demonstraram que a fração de V/VE que chega ao solo de uma clareira é substancialmente maior $(1,2-1,4)$ que a fração que chega ao solo no interior de uma floresta $(0,1$ - 0.5), proporção insuficiente para produção da forma ativa do fitocromo em sementes de espécies pioneiras (Vazquez-Yanes \& Smith 1982).

O fotoperíodo também foi determinante para a germinação das sementes de ambas as espécies, que apresentaram máxima germinação quando expostas a fotoperíodos de no mínimo oito horas diárias de luz em $T$. pulchra, e pelo menos duas horas para $T$. gramulosa . Utilizando diferentes fotoperíodos, que teoricamente corresponderiam a diferentes tamanhos de clareiras, Vazquez-Yanes \& Smith (1982) demonstraram que são necessárias várias horas de exposição diária a altas fontes de irradiação $\mathrm{V}$ para que sementes de Cecropia obtusifolia e Piper auritum germinem totalmente. Este comportamento é de extrema importância em processos de sucessão, por permitir a germinação destas sementes apenas em clareiras suficientemente grandes, nas quais a radiação solar direta (não filtrada pela vegetação) atinja o solo na maior parte do dia. Em florestas tropicais árvores pioneiras como Cecropia e Trema são características somente de clareiras grandes $\left(>500 \mathrm{~m}^{2}\right)$. O fotoblastismo das sementes de árvores pioneiras parece ser extremamente preciso, já que as evidências indicam que o fitocromo tem a potencialidade de detectar a duração dos raios de luz direta que incidem sobre as sementes (Vazquez-Yanes \& Orozco-Segovia 1984). O fitocromo das sementes de plantas pioneiras impede sua geminação quando estas são disseminadas no interior da mata sob o dossel, ficando as sementes em estado de dormência até que ocorram alterações nas condições de luminosidade.

Pompeia et al. (1992), analisando o comportamento de sementes de T. pulchra e T. mutabilis semeadas por via aérea em trecho de Mata Atlântica, verificaram que a distribuição das espécies, após seis meses do lançamento das sementes, se restringiam a áreas com longos períodos de exposição solar diária.

Outra evidência do envolvimento do fitocromo intermediando a germinação das sementes de $T$. pulchra e $T$. granulosa pode ser observada através das curvas de escape. A reversão do fitocromo foi demonstrada irradiando as sementes com VE logo após a irradiação com V e, à medida em que se aumentou o tempo de escape (período de escuro entre a irradiação V e VE), houve incremento na percentagem de germinação. Embora possa ser revertido para sua forma inativa (Fv), quando irradiado com VE, grande parte do fitocromo permanece na sua forma ativa (Fve) durante o período de escuro. O tempo de escape varia de espécie para espécie, como o observado com T. pulchra e T. granulosa, possibilitando, desta maneira, determinar o tempo mínimo necessário para que quantidade suficiente do fitocromo na forma ativa desencadeie o processo da germinação. Os resultados obtidos 
indicam que a ação do fitocromo em sementes de $T$. granulosa é mais rápida que em $T$. pulchra (Fig. 3), no entanto, as duas espécies apresentaram respostas típicas de sementes de espécies arbóreas pioneiras, possivelmente a primeira espécie colonizando clareiras pequenas, e a segunda espécie colonizando somente clareiras maiores.

\section{Agradecimentos}

O primeiro autor foi bolsista do CNPq e o segundo, conta com Bolsa de Pesquisa/ Produtividade Científica pelo CNPq. Este trabalho foi realizado com os auxílios financeiros da FAPESP, FUNDUNESP e CNPq.

\section{Referências bibliográficas}

Augspurger, C. K. 1984. Seedling survival of tropical tree species: interactions of dispersal distance, light-gaps, and pathogens. Ecology 65: 1705-1712.

Bartley, M. R. \& Frankland. B. 1982. Analysis of the dual role of phytocrome in the photoinhibition of seed germination. Nature 300: 750-752.

Brokaw, N. V. L. 1987. Gap-phase regeneration of three pioneer tree species in a tropical forest. Journal of Ecology 75: 9-19.

Calho. A. G.; Silva, L. C. W. \& Torres, A. C. 1989. Ajuste de funções não lineares de crescimento. Revista Brasileira de Fisiologia Vegetal 1: 9-18.

Canham. C. D.; Denslow, J. S.; Platt, W. J.; Runkle, J. R.; Spies. T. A. \& White, P. S. 1990. Light regimes beneath closed canopies and tree-fall gaps in temperate and tropical forest. Canadian Journal Forest Research 20: 620-631.

Casal. J. J. \& Smith, H. 1989. The function, action and adaptive significance of phytochrome in lightgrown plants. Plant Cell and Environment 12: 855-862.

Cone. K. W. 1985. Photocontrol of seed germination of wildtype and long-hypocotyl mutants of Arabidopsis thaliana. Tese de Doutorado. Landbouwhogeschool te Wageningen, Wagenigen.

Cone, J. W. \& Kendrick, R. E. 1986. Photocontrol of seed germination. Pp. 443-466. In R. E. Kendrick \& G. H. M. Kronenberg. Photomorphogenesis in Plants. Martinus Nijhoff, Dordrecht.

Denslow, J. S. 1980. Gap partitioning among tropical rainforest trees. Biotropica 12: 47-55.

Ewel. J. 1980. Tropical succession: mainfold routes to maturity. Biotropica 12: 2-7.

Frankland, B. \& Taylorson, R. 1983. Light control of seed germination. Photomorphogenesis. Spring Verlag, Berlin.

Garwood, N. C. 1983. Seed germination in a seazonal tropical forest in Panama: a community study. Ecological Monographs 53: 159-181.

Goldman. G. H.; Fattori. A. P. \& Januário, M. 1989. Variação espacial e temporal da irradiância solar e da razão entre vermelho e vermelho-extremo que chegam ao solo em diferentes microhabitats na região de Tucuruí, PA. Acta Amazonica 19: 243-248.

Kapos, V.; Pallant, E.; Bien, A. \& Freskos, S. 1990. Gap frequencies in lowland rain forest sites on contrasting soils in Amazonian Ecuador. Biotropica 22: 218-225.

Kendrick. R. E. \& Frankland, B. 1969. Photocontrol of germination of Amaranthus caudatus. Planta 85: 326-329.

Lopes-Quiles, M. M. \& Vazquez-Yanes, C. 1976. Estudio sobre germinacion de semillas en condiciones naturales controladas. Pp. 250-262. In A. Gomez-Pompa; C. Vazquez-Yanes; S. del Amo \& A. Butanda (eds.). Regeneration de Selvas. Continental, México.

Mendonça, R. R.; Pompéia, S. L. \& Martins, S. E. 1992. A sucessão secundária da Mata Atlântica na região de Cubatão, SP. Revista do Instituto Florestal 4: 131-138.

Pompéia, S. L.; Pradella, D. Z. A.: Diniz, K. M. \& Santos. R. P. 1992. Comportamento dos manacás-da-serra (Tibouchina sp.) semeados por via aérea em Cubatão. Revista do Instituto Florestal 4: 505-512.

Rolim. S. G.; Couto, H. T. Z. \& Groke, P. 1992. Análise estrutural de fragmentos de Mata Atlântica em diferentes estádios sucessionais. Revista do Instituto Florestal 4: 152-157.

Smith, H. 1973. Light quality and germination: ecological implications. Pp. 219-231. In W. Heydecker (ed). Seed Ecology. Butterworths, London. 
Smith. H. 1986. The perception of light quality. Pp 187-210. In R. E. Kendrick \& G. H. M. Kronenberg (eds.), Photomorphogenesis in Plants. Martinus Nijholf. Dordrecht.

Snedecor, G. W. \& Cochran. W. G. 1967. Statistical methods. The lowa State University Press, Iowa.

Takaki. M.; Heeringa, G. H.; Cone, J. W. \& Kendrick. R. E. 1985. Analysis of effect of light and temperature on the fluence response curves for germination of Rumex obtusifolius. Plant Physiology 77: 731-734.

Trexler, J. C. ; McCullogh, C. E. \& Travis, J. 1988. How can the functional response best be determined? Oecologia 76: 206-214.

Vazquez-Yanes, C. \& Orozco-Segovia, A. 1984. Ecophysiology of seed germination in the tropical humid forest of the world: a review. Pp. 37-50. In E. Medina: H. A. Money \& C. Vazquez-Yanes (eds.). Physiological Ecology of Plants of the Wet Tropics. [s.I.]: Dr. W. Junk Publishers (Task for Vegetation Science, 12. The Hague)

Vazquez-Yanes, C. \& Orozco-Segovia, A. 1990. Effect of moisture on longevity in seeds of some rain forest species. Biotropica 22: 215-216.

Vazquez-Yanes, C. \& Smith, H. 1982. Phytochrome control of seed germination in the tropical rain forest pioneer trees Cecropia obtusifolia and Piper auritum and its ecological significance. The New Phytologist 92: 477-485.

Vazquez-Yanes, C.; Orozco-Segovia, A.; Rincon. E.; Sanchez-Coronado. M. E.; Huante, P.; Toledo, J. R. \& Barradas, V. L. 1990. Light beneath the litter in a tropical forest: effect on seed germination. Ecology 71: 1952-1958. 